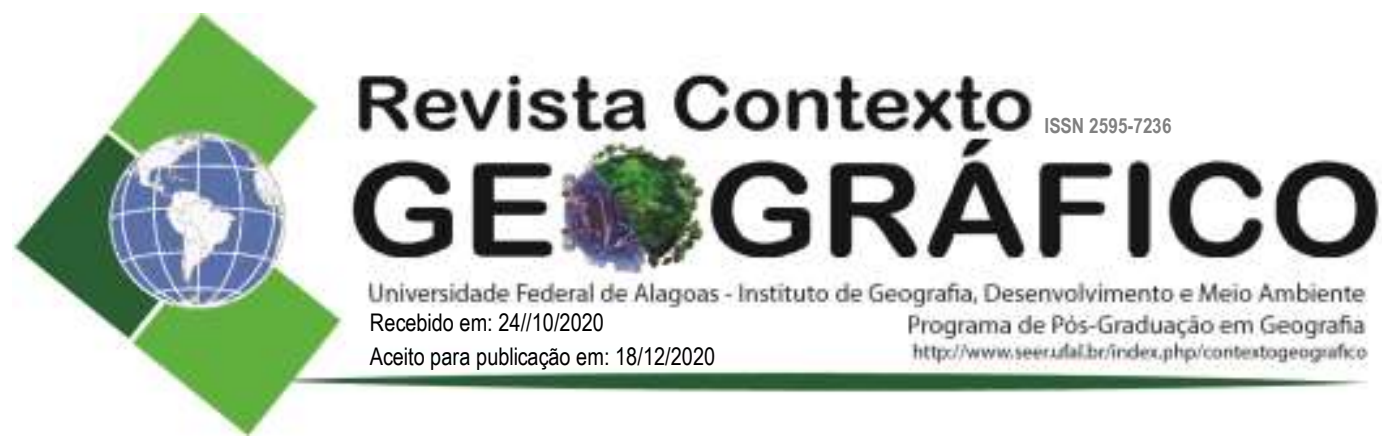

\title{
INTERAÇÕES SOCIOAMBIENTAIS NAS MARGENS DO RIO PARAÍBA DO SUL EM CAMPOS DOS GOYTACAZES/RJ: CONSIDERAÇÕES SOBRE O CASO DA INDÚSTRIA CORBION
}

\author{
Luca Lämmle \\ Doutorando da Universidade Estadual de Campinas - UNICAMP, Instituto de Geociências, \\ Departamento de Geografia, São Paulo, Brasil \\ lucalammle@ige.unicamp.br
}

Cleber de Jesus Santos

Doutorando da Universidade Estadual de Campinas - UNICAMP, Instituto de Geociências, Departamento de Geologia e Recursos Naturais, São Paulo, Brasil

cleber.geofisico@gmail.com

Joaquim Ernesto Bernardes Ayer

Professor do Centro Universitário de Paulinia - UNIFACP, São Paulo, Brasil

joaquimeba@gmail.com

Antonio Ivo Gomes Barbosa

Mestre em Geografia pela Universidade Federal Fluminense (UFF), Instituto de Ciências da Sociedade e Desenvolvimento Regional, Departamento de Geografia, Rio de Janeiro, Brasil

antonioivo@id.uff.br

\begin{abstract}
RESUMO - As diferentes arenas de discussão que sustentam o conceito de Desenvolvimento Sustentável demonstram a variedade de possibilidades para se pensar este tema. Adentrar a essas discussões significa tratar das inter-relações que tangem a sociedade, o meio ambiente e as instancias políticas do território. Com isso, uma sistematização baseada em alguns autores torna-se um elemento importante quando se propõe trabalhar em cima desta conceituação. O objetivo da discussão é direcionado para as questões de apropriação social e de recursos naturais no município de Campos dos Goytacazes/RJ. O principal agente que ilustrará a aplicação destes conceitos em uma perspectiva empírica, é a empresa de sede holandesa denominada Corbion, especializada na preservação natural de alimentos e a maior produtora de ácido láctico da América Latina. Procura-se, também, demonstrar como se dá a apropriação do discurso da chamada "Ecoeficiência" pela empresa, que atende ao mercado da América Latina com uma das unidades Industriais em Campos dos Goytacazes (RJ). Não há informações suficientes para apontar a elegibilidade da empresa nesta área, porém, podemos indagar as consequências da implementação.
\end{abstract}

Palavras-chave: Recursos Naturais; Desenvolvimento Sustentável; Interações Socioambientais.

\section{SOCIOENVIRONMENTAL INTERACTIONS IN THE MARGINS OF THE PARAÍBA DO SUL RIVER IN CAMPOS DOS GOYTACAZES/RJ: CORBION INDUSTRY CASE CONSIDERATIONS}

\footnotetext{
ABSTRACT - The different arenas of discussion that underpin the concept of Sustainable Development demonstrate the variety of possibilities for thinking about this theme. Entering these discussions means addressing the interrelationships that affect society, the environment, and the
} 
LAMMLE, L.; SANTOS, C. J.; AYER, J. E. B.; BARBOSA, A. I . G.

\begin{abstract}
political instances of the territory. Thus, a systematization based on some authors becomes a important element when proposing to work on this conceptualization. The objective of the discussion is directed to the issues of social appropriation and natural resources in the city of Campos dos Goytacazes/RJ. The main agent that will illustrate the application of these concepts from an empirical perspective is the Dutch-based company called Corbion, which specializes in natural food preservation and the largest producer of lactic acid of Latin America. It also seeks to demonstrate how the company appropriates the so-called "Eco-efficiency" discourse, which serves the Latin American market one of the Industrial units in Campos dos Goytacazes/RJ. There is not enough information to indicate the company's eligibility in this area, but we can ask the consequences of implementing this.
\end{abstract}

Keywords: Natural Resources; Sustainable Development; Socioenvironmental Interactions.

\title{
INTRODUÇÃO
}

Com o desencadear da revolução industrial e o aperfeiçoamento das formas de produção e mudanças no padrão de consumo a partir do século XVIII, intensificou-se o impacto ambiental de origem antrópica e os riscos a estes associados (COELHO, 2006), tornando a ideia de sustentabilidade cada vez mais comum. As diferentes arenas de discussão que sustentam o conceito de Desenvolvimento Sustentável demonstram a variedade de possibilidades para se pensar este tema. Com isso, uma sistematização baseada em alguns autores torna-se um elemento importante quando se propõe trabalhar em cima desta conceituação.

Adentrar à essas discussões significa tratar das inter-relações que tangem a sociedade, o meio ambiente e as instancias políticas do território. Este conceito tornou-se muito popular no debate contemporâneo, sobretudo após a chamada "Crise Ambiental" apontada, dentre outros, por Folladori (2011), que acabou por impulsionar os questionamentos sobre impactos ambientais. Diante disso, atentar-se sobre a produção do espaço urbano torna-se um dos eixos possíveis de debater o desenvolvimento sustentável, visto que neste processo confrontam-se diferentes agentes.

O foco deste trabalho está nos processos produtivos do espaço e sua configuração históricoterritorial da "Macrozona de Proteção Ambiental" do rio Paraíba do Sul, área definida pelo Plano Diretor do Município de Campos dos Goytacazes de 2008 e atualizado em 2019. Contudo, tal delimitação, que deveria ser voltada a proteção do meio ambiente próximo ao canal principal do rio, acabou sendo apropriada por instituições públicas, indústria e comercio, além de comunidades que se estabeleceram na área historicamente. Nesse sentido, o uso e ocupação desta zona de proteção ambiental, acaba por gerar uma série de impactos ambientais negativos, tanto no âmbito natural quanto social.

Impactos Ambientais é o resultado do efeito da ação antrópica sobre algum componente biótico ou abiótico, podendo ser estes positivos ou negativos (SANTOS, 2004). Cabe ressaltar que todas essas apropriações envolvem externalidades negativas (impactos ambientais negativos) e que existem técnicas para mitigá-los, mas normalmente as soluções possuem custo elevado e são difíceis de calcular os prejuízos ambientais ocasionados. Em atividades industriais, os principais impactos negativos produzidos estão relacionados ao elevado consumo de água, poluição atmosférica, contaminação das águas superficiais pela deposição de efluentes e resíduos sólidos (BRASIL, 2012), e estão diretamente relacionados com os impactos causados por diferentes ramos da indústria.

Para tal discussão, foi recortado o principal agente que ilustrará a aplicação destes conceitos em perspectiva empírica, sendo este a empresa de sede holandesa Corbion (antes chamada de Purac - Sínteses Indústria e Comércio Ltda), especializada na preservação natural de alimentos e a maior produtora de ácido láctico da América Latina (BOOTZ, 2010), atendendo o ao mercado do Brasil e América Latina com uma de suas unidades industriais em Campos dos Goytacazes, no norte fluminense. A empresa está instalada no município em questão há mais de 20 anos, passando por ampliação significativa no ano de $2005^{1}$, ocasião em que aumentou significativamente sua infraestrutura e capacidade produtiva. 
LAMMLE, L.; SANTOS, C. J.; AYER, J. E. B.; BARBOSA, A. I . G.

Considerando o relatório técnico da Agência da Bacia do Rio Paraíba (AGEVAP, 2012, p.326): "Os maiores lançamentos de carga orgânica no município em 2009 foram o Grupo Águas do Paraíba (837.713 kg/ano) e PURAC - Sínteses Indústria e Comércio Ltda (atualmente chamada de Corbion) (56.940 kg/ano)" sendo considerados parâmetros: Materiais Oxidáveis, Sólidos em Suspensão, Toxicidade, Fósforo Total e Nitrogênio Total, todos com efeitos poluidores e agravantes da eutrofização. Apesar do levantamento ter sido realizado em 2012, sugere-se que ainda exista lançamentos de dejetos em quantidade significativa devido ao seu grande porte industrial, ainda que a mesma tenha adotado medidas no sentido de reduzir tal impacto ambiental.

O objetivo desta discussão é direcionado para questões de apropriação social de recursos naturais por parte da empresa, demonstrando como se dá a apropriação do discurso da chamada "Ecoeficiência" para criar uma imagem positiva de sustentabilidade do empreendimento industrial e agregar valor aos seus produtos. A, com a hipótese de que a empresa se apropria do discurso da "Ecoeficiência" e desenvolvimento sustentável, mas, na prática, não realiza ações efetivas proporcionalmente aos impactos negativos causados na área. Além disso, é possível que os resíduos gerados, quando descartados em águas superficiais, podem provocar alterações físico-químicas e causar, por exemplo, intoxicação de peixes e pressão sobre a biodiversidade, tendo em vista a localização nas margens do rio Paraíba do Sul. Por fim, são apontadas possibilidades sustentáveis para o tratamento de alguns efluentes como forma de reaproveitamento de dejetos e diminuição de impactos ambientais negativos.

\section{ECOEFICIÊNCIA, DESENVOLVIMENTO SUSTENTÁVEL E INTERAÇÕES SOCIOAMBIENTAIS}

A área de estudo corresponde ao município de Campos dos Goytacazes -RJ, o qual está integrado à Mesorregião Norte Fluminense do estado do Rio de Janeiro, juntamente com os municípios de Carapebus, Cardoso Moreira, Conceição de Macabu, Macaé, Quissamã, São Fidélis, São Francisco de Itabapoana e São João da Barra (Figura 1) (IBGE, 1990). A expansão do núcleo urbano ocorreu em paralelo com o crescimento de habitações precárias nas margens do rio Paraíba do Sul, principalmente a partir da construção do Porto da Cadeia, onde passou a ocorrer a rotatividade de embarcações de transporte de cargas e pessoas, com a primeira grande enchente em 1833 foram construídas muralhas de proteção (LOPES, 1988).

A área que se localiza a Corbion (Figura 1) também abriga uma faixa contínua de favelização, denominadas e localizadas na seguinte ordem: Patronato; Tira Gosto; Siqueira e Silva; Risca Faca e Matadouro. A favela do Patronato é vizinha da indústria e é contígua a todas as outras. Parte desta faixa de favelização está em assentada sobre um dique de contenção construído às margens do Rio Paraíba do Sul e, em parte, ocupa uma faixa de terreno ao longo deste. Inicialmente, esta área foi ocupada por funcionários do Matadouro Municipal e os domicílios eram de madeira (FARIA, 2005).

No âmbito da metodologia da pesquisa, optou-se por um estudo do tipo qualitativo. Sendo assim, se trata de um trabalho analítico e explicativo, identificando fatores determinantes ou contributivos ao desencadeamento dos fenômenos (GIL, 2007). Para mais, adotou-se os seguintes procedimentos: pesquisa bibliográfica em documentos municipais (relatórios, teses, artigos e dissertações); agência de monitoramento (comitê de bacia hidrográfica do rio Paraíba do Sul); Trabalho de campo a fim de identificar possíveis emissões de efluentes na área e mapeamento baseado no plano diretor municipal.

Em relação a fundamentação teórica, foca-se em algumas discussões para o entendimento da evolução da área estudada e os debates em torno da problemática analisada, sendo estas: Desenvolvimento sustentável; apropriação de recursos, ecoeficiência, e outras discussões afins. Assim, pode-se traçar um breve questionamento a respeito dessa temática, que envolve meio ambiente, sociedade, e a interação, a partir da dinâmica de uma grande indústria transnacional inserida em um contexto local 
Figura 1. Localização da área de Estudo

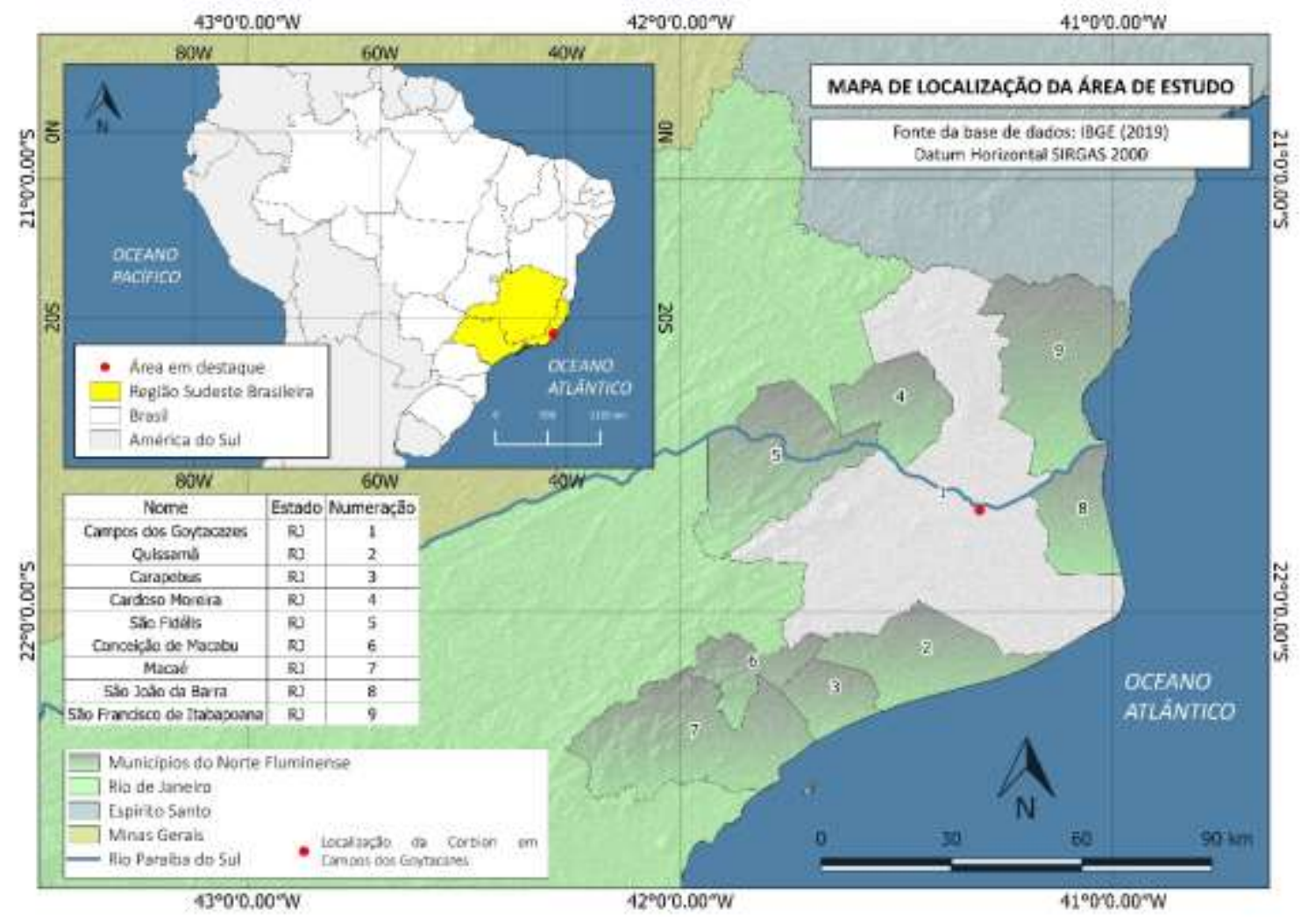

Elaboração: os Autores (2020).

A ecoeficiência, enquanto diretriz para o desenvolvimento sustentável, baseia-se na ideia de otimizar a produção de bens e serviços sustentáveis e, ao mesmo tempo, reduzir o uso de recursos naturais, a produção de resíduos e consequentemente o impacto ambiental (DESIMONE; POPOFF, 2000). Segundo Dias (2006), ecoeficiência é um sistema estratégico produtivo que promove o fornecimento de bens e serviços sustentáveis a preços competitivos que satisfazem as necessidades humanas, e assim promove a redução dos impactos ambientais e de consumo de recursos naturais.

Este conceito, ainda segundo o autor, prescinde da implementação de um sistema de gestão ambiental de forma a reorientar processos com vistas a diminuir os custos, evitar riscos ambientais, evitar riscos à saúde dos funcionários e clientes, reduzir a poluição e garantir a manutenção de recursos naturais. Este conceito possui oito diretrizes:

1. Minimizar a intensidade de materiais dos bens e serviços;

2. Minimizar a intensidade energética de bens e serviços;

3. Minimizar a dispersão de tóxicos;

4. Fomentar a reciclabilidade dos materiais;

5. Maximizar a utilização sustentável de recursos renováveis;

6. Estender a durabilidade dos produtos;

7. Aumentar a intensidade de serviço dos bens e serviços;

8. Promover a educação dos consumidores para um uso mais racional dos recursos naturais e energéticos.

Desta forma, objetivou-se indicar algumas concepções utilizadas nos discursos de sustentabilidade, para que não haja distorções e sobreposição de agentes nos processos de ocupação de espaços protegidos, o que torna difícil o estabelecimento de propostas e soluções para os problemas ambientais derivados dele. 
LAMMLE, L.; SANTOS, C. J.; AYER, J. E. B.; BARBOSA, A. I . G.
INTERAÇÕES SOCIOAMBIENTAIS NAS MARGENS DO RIO PARAÍBA DO SUL EM CAMPOS DOS GOYTACAZES/RJ: CONSIDERAÇÕES SOBRE O CASO DA INDÚSTRIA CORBION

\section{Crise ambiental: como caracterizá-la?}

Ao pensarmos sobre Desenvolvimento Sustentável, devemos recorrer aos seus precedentes, em busca de um ponto de partida para as discussões que alcançaram todas as escalas, dentro dos debates apoiados na questão ambiental, que, conforme aponta Folladori (2001, p.102): “[...] tem a particularidade de ser tão ampla e de seus elementos estarem tão interconectados que sua delimitação não é tarefa fácil". Portanto, o autor sistematiza alguns problemas recorrentes na literatura e os elenca como "Indicadores da Crise Ambiental", mesmo ressaltando que pode haver problemas metodológicos quanto ao agrupamento desses indicadores. Outro problema grifado pelo autor seria a redutibilidade destes nos relatórios no que tratam a poluição, a depredação e o excesso de população como síntese da crise ambiental.

Dentre os principais indicadores da referida crise ambiental, estão presentes na lista a devastação das matas, contaminação da água, contaminação de costas e mares, exploração de mantos aquíferos, erosão de solos, desertificação, perda da diversidade agrícola, destruição da camada de ozônio, e o aquecimento global do planeta. Se nos basearmos nestes indicadores mencionados, o que mais se enquadra na temática deste trabalho é a contaminação da água, uma vez que um dos agentes presentes no recorte emitem diretamente no Rio Paraíba do Sul os dejetos e poluentes provenientes do processo de fabricação de seus produtos. Tais problemas ambientais se apresentam de múltiplas maneiras e podem ser reduzidos a depredação de recursos, como no caso das águas do Rio Paraíba do Sul.

Em contrapartida, quando percebemos o problema ambiental pela ótica social de produção do espaço, temos a superpopulação e pobreza como principais chaves de análise, visto que dentro deste trabalho existem agentes sociais que não estão plenamente incorporados ao ciclo do capital e que as precárias condições estruturais de suas moradias impactam diretamente nas margens/águas do rio, tratado aqui como fonte de recursos.

Neste sentido, percebemos que, se há uma problemática ambiental, deve ser considerada nas diferentes escalas e a partir de seus mais distintos agentes. Mesmo que certo posicionamento seja cobrado, é importante que estejamos atentos às sobreposições existentes dentro de uma problemática, sobretudo quando ela carrega uma diversidade de interpretações tal qual a questão ambiental.

\section{Desenvolvimento sustentável}

Para começarmos a tecer considerações sobre quais são as principais arenas de discussão acerca do desenvolvimento sustentável na atualidade, faz-se necessário retomar algumas discussões apontadas pelos autores que compões a bibliografia deste trabalho. O termo foi utilizado pela primeira vez, em 1983, por meio da Comissão Mundial sobre Meio Ambiente e Desenvolvimento criada pela ONU. Presidida, na ocasião, pela primeira-ministra da Noruega (Gro Harlem Brudtland), foi proposto que o desenvolvimento econômico fosse integrado à questão ambiental, estabelecendo-se, assim, o conceito de "desenvolvimento sustentável".

Os trabalhos foram finalizados em 1987, com a apresentação de um diagnóstico dos problemas ambientais globais, conhecido como "Relatório Brundtland". Na Eco-92 (Rio-92), essa nova forma de desenvolvimento foi amplamente difundida e aceita, e o termo ganhou força. Scotto et al. (2007) apontam a dificuldade de sistematização, devido à escassez teórica pautada no conceito de Desenvolvimento sustentável, agravando a ambiguidade de seus significados. Tendo em vista este fenômeno, nem todos vão entender os argumentos chaves deste conceito da mesma maneira.

Wolfgang Sachs (1997) discute três óticas diferenciadas de se pensar o desenvolvimento sustentável: I - A Perspectiva da Competição, na qual os países periféricos seriam os grandes promotores de problemas globais, devendo o crescimento econômico promover a força competitiva para aquecer o mercado, resultando na redefinição do problema ambiental; II - A Perspectiva do Astronauta, apontando para uma "Institucionalidade Global" como forma e gestão e manutenção dos problemas de insustentabilidade mundiais; III - A Perspectiva 
LAMMLE, L.; SANTOS, C. J.; AYER, J. E. B.; BARBOSA, A. I . G.
INTERAÇÕES SOCIOAMBIENTAIS NAS MARGENS DO RIO PARAIIBA DO SUL EM CAMPOS DOS GOYTACAZES/RJ: CONSIDERAÇÕES SOBRE O CASO DA INDÚSTRIA CORBION

Doméstica, que indica a sociedade contemporânea de consumo promotora da desigualdade, resultando em injustiça socioambiental.

Assim como ele, outros autores (Young; Motta, 1995; Viola, 1996; Reed, 1996) propõem formas de entendimento sobre Desenvolvimento Sustentável que, por vezes, divergem ou convergem, ressaltando a ambiguidade. Cabe a este trabalho aplicar nas diferentes perspectivas oferecidas os atores sociais que constroem o espaço analítico da pesquisa. Neste sentindo, a abordagem pautada na ecoeficiência e na competição de mercado por meio da inovação atingiu muitos meios simbólicos de comunicação contemporâneos, tornando-se uma justificativa muito popular, sobretudo entre as empresas multinacionais, naquilo que tange as suas práticas relacionadas aos problemas ambientais. Também é levando em conta as práticas sociais e territorializações que estão impressas no recorte de estudo, direcionando as indagações para uma perspectiva de justiça social e compensação ambiental.

Para melhor detalhamento do objeto do trabalho, é possível começar a elencar as principais chaves que vão sustentar a análise das interações nas margens do Rio Paraíba do Sul. A primeira delas abrange as "externalidades" tendo em vista os dois lados passiveis de serem entendidos (positivas ou negativas), que retratam as ações de uns autores sociais sobre os outros, conforme apontam Scotto et al. (2007). O processo produtivo normalmente envolve alguma externalidade negativa, mesmo que busque tecnologias mais modernas e limpas de produção. Contudo, estas medidas são caras e problemáticas de serem contabilizadas quando se trata da matériaprima/recurso natural. Portanto, agregar valor a um produto (custo empresarial) com base nas externalidades, torna-se uma medida complicada, porém, com um viés lucrativo quando ferramentas de mídia e propaganda se valem destes mecanismos para promover estas empresas. O que se questiona neste trabalho é a validade da internalização destes conflitos e sua eficiência prática no ambiente, além do direito de propriedade dos recursos, que no caso desta pesquisa específica são as águas do Rio Paraíba do Sul, além da compensação monetária aos danos.

\section{Interações socioambientais nas margens do rio Paraíba do Sul}

Nesta seção, propõe-se a análise das relações entre os atores sociais presentes nas margens do Rio Paraíba do Sul (no que tange ao município de Campos dos Goytacazes/RJ) pautados nas diferentes perspectivas de Desenvolvimento Sustentável, além de considerações da evolução territorial sobre a área de estudo, levando em conta as práticas humanas e culturais que se imprimem nele.

Localizando-se no mapa de macrozoneamento formulado pelo Plano Diretor Municipal de 2019 (Figuras 2 e 3), os territórios da empresa Corbion e a comunidade Tira Gosto (localizada nos fundos e entorno da indústria) estão inseridos parcialmente em uma Macrozona de Proteção Ambiental, que, segundo o artigo 158, do capítulo 2, referente ao Macrozoneamento Urbano, esta zona é delimitada para "[...] área protegidas ou de interesse de proteção ambiental que, por suas características ambientais, bens e serviços, e de beleza cênica não poderão ser parceladas e ocupadas para fins urbanos e para quais serão incentivadas ações de recuperação e conservação ambiental [...]" tais como "[...] áreas urbanas sujeitas a inundação e consideradas como de risco à vida humana [...]" nas quais podemos inserir principalmente a comunidade da "Tira Gosto" e as comunidades contíguas. Vale ressaltar que a comunidade é anterior ao plano diretor municipal, e tal instrumento foi importante para evitar adensamento ainda maior no entorno do canal do rio Paraíba do Sul. Contudo, esgoto a céu aberto e lixo no canal fluvial foram verificados em campo, sendo este um componente a mais nos impactos ambientais negativos da área de estudo.

Nesse contexto, não há informações suficientes para apontar a elegibilidade da empresa nesta área, tendo em vista que sua instalação foi anterior às diretrizes ambientais do plano diretor municipal atual, porém, podemos indagar as consequências desta, visto que faz fronteira direta com uma comunidade, criando tensões e agravando problemas ambientais, pois, se a infraestrutura precária das comunidades afeta diretamente as águas e margens do Rio Paraíba do Sul, o lançamento de insumos industriais poderia agravar ainda mais essa problemática. Nesse sentido, apesar das 
LAMMLE, L.; SANTOS, C. J.; AYER, J. E. B.; BARBOSA, A. I . G.
INTERAÇÕES SOCIOAMBIENTAIS NAS MARGENS DO RIO PARAÍBA DO SUL EM CAMPOS DOS GOYTACAZES/RJ: CONSIDERACÕES SOBRE O CASO DA INDÚSTRIA CORBION

atividades industriais da empresa afetar em algum grau a questão ambiental, se trata também de um problema estrutural de desenvolvimento e planejamento urbano ao longo da história do município.

Conforme o mapa de áreas para aplicação dos instrumentos indutores de desenvolvimento urbano disponível no Plano Diretor (Figura 2), estas áreas não possuem a outorga onerosa do direito de construir, não sendo consideradas áreas com potencial de adensamento, logo, não haverá projetos de infraestrutura urbana previstos.

Figura 2. Macrozoneamento urbano completo no distrito sede de Campos dos Goytacazes/RJ

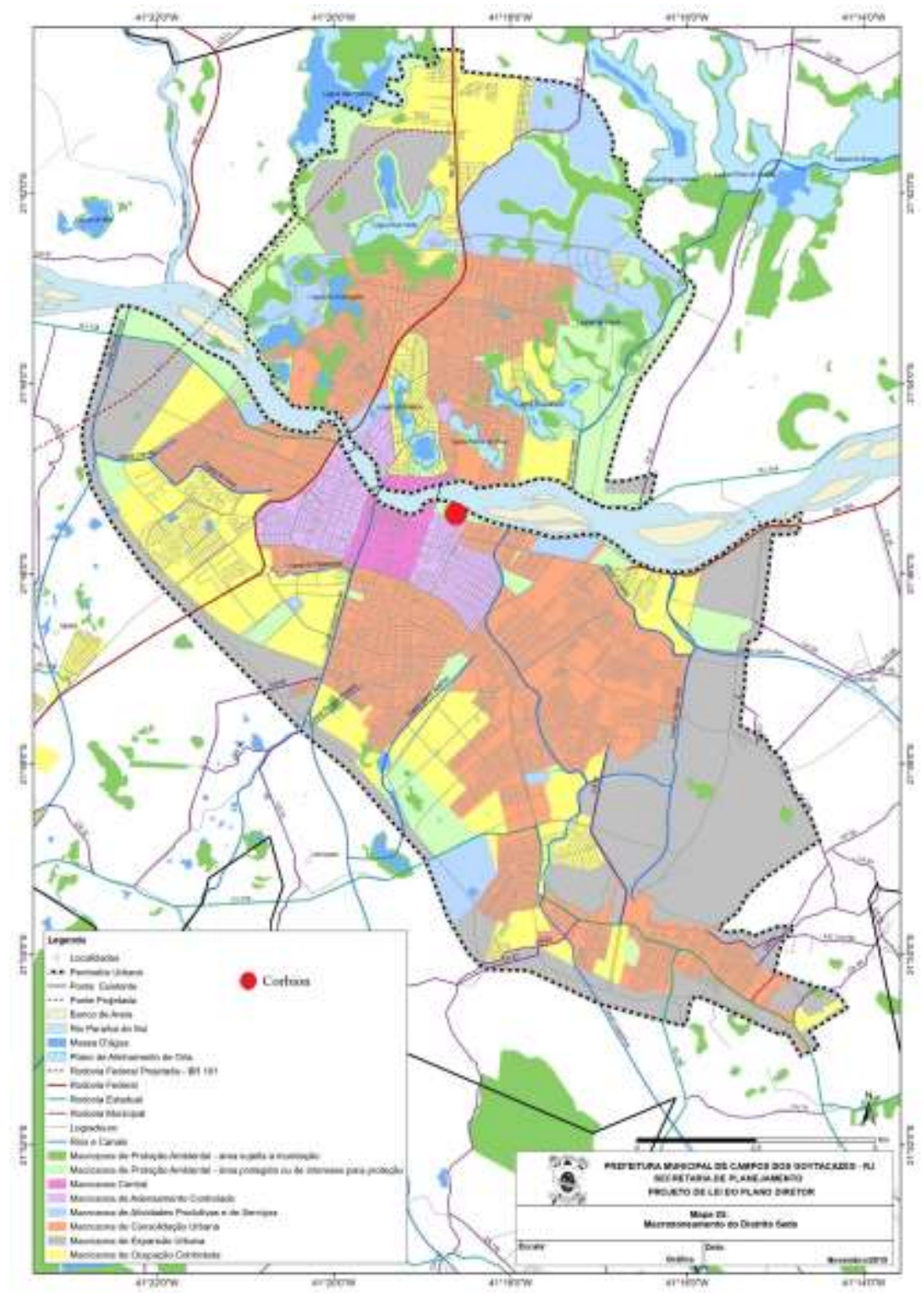

Fonte: Plano diretor de Campos dos Goytacazes/RJ (2019). Org.: Autores (2020)

De acordo com Scotto (1997) podemos considerar que os recursos da natureza, dos quais depende direta ou indiretamente a vida das populações, são bens coletivos, isto é, pelo menos em tese não podem ser apropriados por um indivíduo ou um grupo de pessoas. Este fenômeno encaixa-se na discussão sobre o direito de propriedade sobre os recursos e as compensações monetárias aos danos, tratando-se de externalidades conforme discutimos na seção anterior. 
Além disso, a própria presença da comunidade se faz de maneira ilegal quando confrontamos o Plano Diretor e os mapas de uso do solo. Após esse breve apontamento, foi possível notar a forma com que a empresa se apropria, de forma relativa, do discurso da ecoeficiência pautada na inovação para garantir competitividade frente ao mercado. Para tanto, baseamos nossas considerações em seu material de marketing que se apresenta com caráter informativo, acessado em 2018. Tal fato não invalida as ações voltadas ao meio ambiente que a empresa realiza, porém se faz contraditória à determinadas diretrizes sancionadas pelo próprio município.

Segundo o seguinte fragmento de sua página online acessada em 2018, em tradução livre, a empresa inicia da seguinte forma:

\begin{abstract}
"Na Corbion, a sustentabilidade está no coração do que fazemos - e valorizamos demonstrá-la todas os dias em toda a nossa cadeia, trabalhando para reduzir o impacto ambiental de nós e os nossos parceiros em áreas como resíduos, água e energia. Nós medimos o nosso desempenho de sustentabilidade com base na proteção do ambiente e bem-estar social, bem como o desempenho econômico [...]. Com processos sustentáveis, estamos cada vez mais usando tecnologias inovadoras e eficientes em termos de recursos com base em recursos renováveis que causem menos desperdício e não interferem na a cadeia alimentar". (Corbion 2018).
\end{abstract}

Nota-se que o discurso ambiental da empresa não condiz com todas as práticas da mesma, começando pela localização de implantação, onde está parcialmente inserida em área de proteção ambiental nas margens do rio Paraíba do Sul (Figura 3). Entretanto, vale ressaltar que a implantação da Corbion foi viabilizada pelo município, fato que transfere parte da responsabilidade para a gestão pública, a mesma que determina as diretrizes na elaboração do Plano Diretor municipal e posteriormente concede esse tipo de outorga.

Figura 3. Mapa de macrozoneamento em escala aproximada, destacando limite entre a macrozona de adensamento controlado (residencial) e macrozona de proteção ambiental (também chamada de setor especial de preservação)

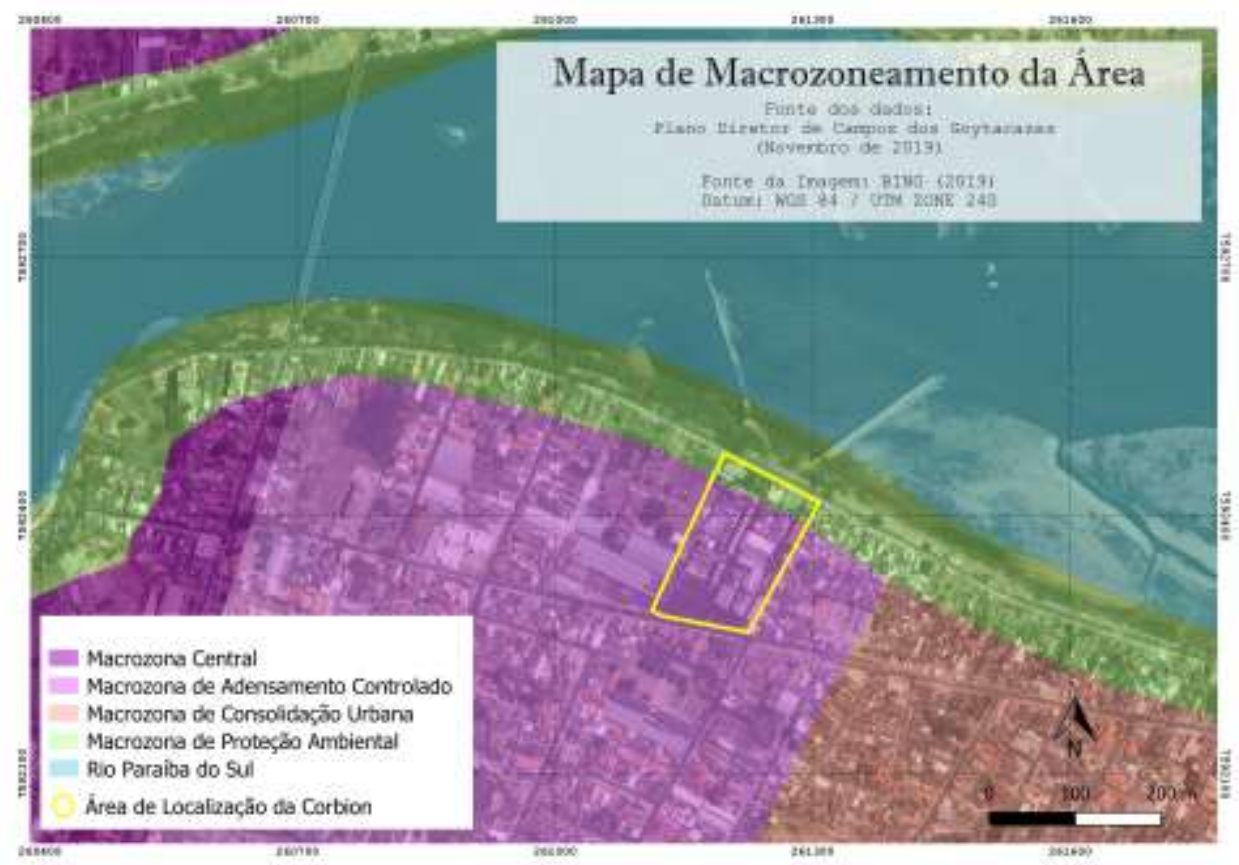

Elaboração: os Autores (2020). 
LAMMLE, L.; SANTOS, C. J.; AYER, J. E. B.; BARBOSA, A. I . G.
INTERAÇÕES SOCIOAMBIENTAIS NAS MARGENS DO RIO PARAÍBA DO SUL EM CAMPOS DOS GOYTACAZES/RJ: CONSIDERAÇÕES SOBRE O CASO DA INDÚSTRIA CORBION

É nesse sentido que destacamos a apropriação de um discurso que segue uma das linhas de pensamento demonstradas no início deste trabalho, a chamada Ecoeficiência, termo que, conforme Scotto (2007) e Carvalho e Gimarães (2007) apontaram, foi criado em 1992 pelo World Business Council for Sistainable Development (WSBCSD).

\section{EXEMPLO DE IMPACTOS DA INDÚSTRIA QUÍMICA E POSSIBILIDADES SUSTENTÁVEIS}

Silva et al. (2005) destacam que as atividades produtivas na área de química "[...] são normalmente de risco e potenciais causadoras de poluição, visto que trabalha com substâncias muitas vezes tóxicas e/ou inflamáveis e após um processo químico normalmente geram um "lixo tóxico" que precisa ser tratado (resíduo). Após um processo químico pode-se: a) encaminhar os resíduos para as estações de tratamento, onde é feito o ajuste das cargas emitidas aos parâmetros estabelecidos para os lançamentos; b) reciclar ou reutilizar os resíduos; e, c) incinerar os resíduos tratados". Um dos principais problemas da indústria química está relacionado com a utilização de solventes orgânicos (voláteis ou não) em seus processos, já que, dependendo do solvente utilizado, sua manufatura, transporte, estoque, manuseio e descarte representam aspectos que demandam cuidado e capital.

A utilização de água como solvente costumava ser descartada dos estudos de reações orgânicas por diversas razões. Entre elas, podem ser citadas a insolubilidade dos reagentes, a sua incompatibilidade com os intermediários e a competição da reação desejada com processos de hidrólise dos reagentes. No entanto, a maioria dos processos bioquímicos ocorre em água, e as diversas reações levaram os químicos a levantar a potencialidade do seu emprego como meio em reações orgânicas (SOUZA et al., 2005). A crítica aqui é feita no sentido de demonstrar que a empresa pode promover inovação ainda mais efetiva no âmbito da sustentabilidade a fim de tornar sua presença dentro deste recorte espacial menos impactante, além da falta de regulamentação do espaço urbano pautado no Plano Diretor (está localizada parcialmente na Macrozona de proteção ambiental).

Nesse contexto, sugere-se que a gestão dos recursos hídricos por parte do poder público e privado na área estudada, assim como em outras áreas, pode melhorar bastante no que tange ao planejamento e infraestrutura, principalmente em relação ao saneamento, tendo em vista que existem tubulações expostas com lançamentos de efluentes diretamente no canal principal do rio Paraíba do Sul em diversos pontos da cidade, sendo um deles nas proximidades da indústria e comunidade de entorno (Figura 4).

A geração de resíduos e efluentes depende fundamentalmente das matérias primas e dos processos de produção. No caso da Corbion, o processo de fermentação do ácido lático pode gerar, por exemplo, considerável quantidade de gesso (CaCO3), FERKAL e PURAGYS (CaSO4.H2O). A similaridade entre os resíduos desperta o interesse na utilização do Ferkal para fins agrícolas, por exemplo, tendo em vista a comprovada viabilidade da aplicação do gesso no processo produtivo agrícola (BORKERT et al., 1987; BRAGA et al., 1995). Como forma de se auto sustentar parcialmente em relação a, pelo menos, parte dos resíduos produzidos, a empresa poderia promover ações de mitigação para reutilização desses resíduos para fins agrícolas, identificando por exemplo, espécies que se adaptam melhor a esse tipo de resíduo no cultivo. Tal ação estaria de acordo com a proposta destacada por Souza et al. (2005).

Figura 4. Tubulação com lançamento de efluentes no canal principal do rio Paraíba do Sul. Destaca-se que a imagem é para ilustrar a existência de lançamento de efluentes diretamente no canal do rio próximo á área da empresa, não necessariamente sendo oriundos da mesma 


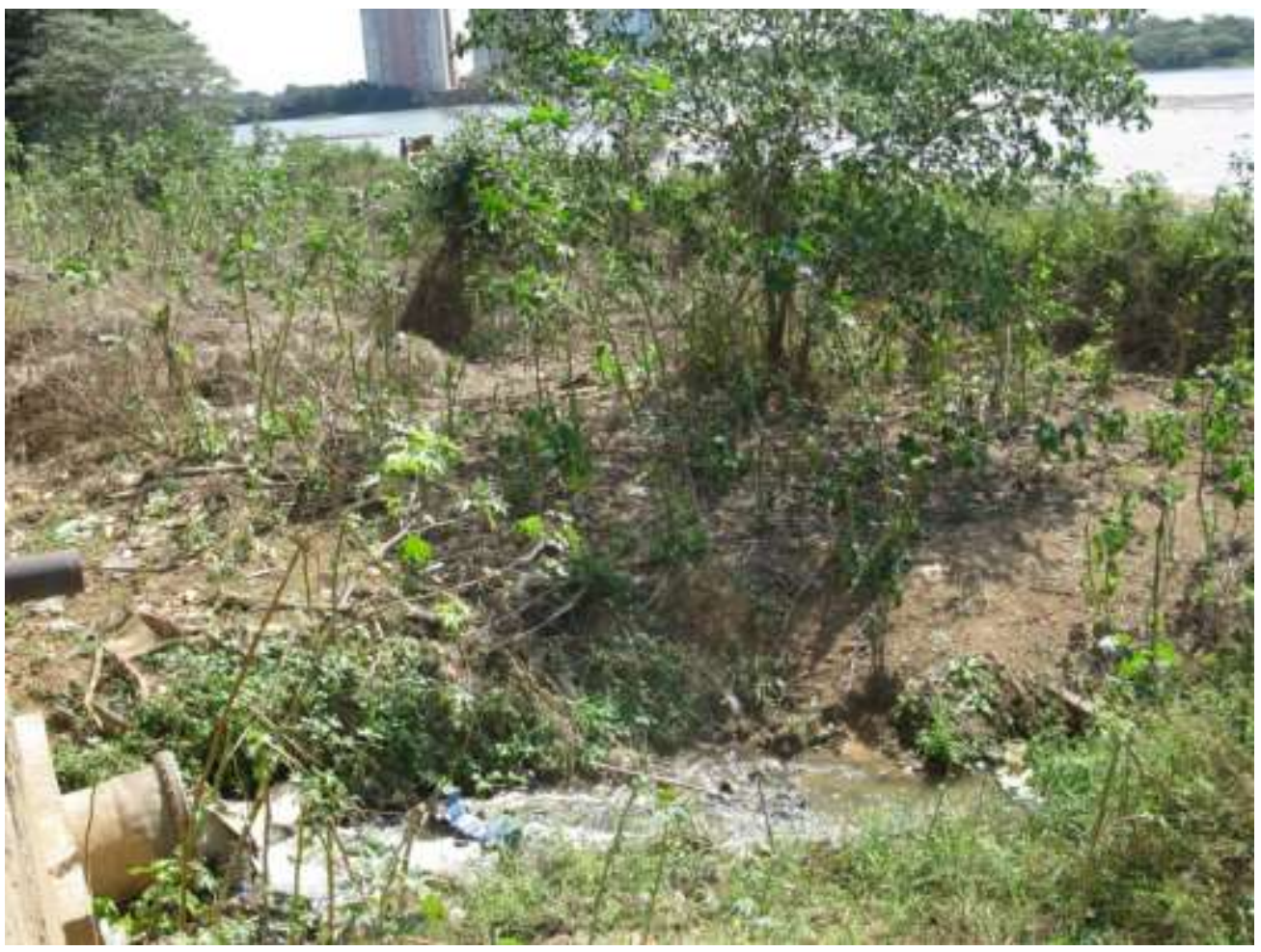

Elaboração: os Autores (2020)

Experiências de sucesso tem sido realizada no intuito de aproveitar estes resíduos na agricultura, sobretudo para resolver problemas de solidificação, salinização e fertilidade; sendo que o PURAGYS também pode ser utilizado para alimentação animal causando assim impactos positivos, como destacado por Pralon e Martins (2001). Boni et al. (2014) mencionam que as espécies da família das leguminosas são reconhecidas como eficientes melhoradoras das características físico-químicas do solo, pois promovem a produção de grande quantidade de biomassa, além de uma vasta exploração do subsolo pelo sistema radicular, acarretando a maior agregação do solo e aumentando a capacidade de retenção de água. Sendo assim, sabe-se que, de um lado, existem resíduos que podem ser reaproveitados; e de outro, espécies que se adaptam a estes resíduos e trazem benefícios para o ambiente.

\section{CONSIDERAÇÕES FINAIS}

No processo da globalização da economia, a natureza se caracteriza como "mercadoria", que rompendo fronteiras políticas e comerciais, associado à uma visão ecológica de mundo. A escala de análise deixa de ser local, regional ou nacional para ser globalizada. Entretanto, analisar a natureza na escala global não significa que devemos deixar de lado a escala local, uma vez que esta possui uma dupla identidade: uma própria (não redutível em escala planetária) e uma identidade comum (que faz parte de uma identidade globalizada a partir de uma abordagem sistêmica). A escala pode ser entendida como medida que confere visibilidade aos fenômenos ambientais.

Quando produzimos uma revisão pautada nos principais elementos teóricos dos textos selecionados para este estudo, a primeira indicação que temos é que a questão ambiental está circundada de significâncias e está sujeita a interpretações diferenciadas. Neste sentido, encontramos categorias e temas que apontam para a dificuldade de sistematização e aplicação sobre os conflitos que surgem das diferentes inter-relações que tangem a sociedade, o meio ambiente, as instâncias políticas, o território e a cultura. Optar por descrever de maneira mais aprofundada estes elementos, se torna uma tarefa relativamente arriscada, tendendo ao reducionismo dos fatos em uma questão complexa. 
LAMMLE, L.; SANTOS, C. J.; AYER, J. E. B.; BARBOSA, A. I . G.
INTERAÇÕES SOCIOAMBIENTAIS NAS MARGENS DO RIO PARAIIBA DO SUL EM CAMPOS DOS GOYTACAZES/RJ: CONSIDERAÇÕES SOBRE O CASO DA INDÚSTRIA CORBION

É importante demonstrar o quanto são necessárias mudanças de perspectiva para o entendimento de um caso empírico, e, neste sentido, o trabalho contempla seu objetivo, considerando as relações socioambientais nas margens do rio Paraíba do Sul no município de Campos dos Goytacazes/RJ a partir de um recorte espacial no município, a partir do comportamento da indústria química presente neste contexto. Soma-se a isso as possibilidades sustentáveis viáveis na indústria química, em que parte do resíduo gerado pode passar por determinados processamentos e ser reutilizado para outros fins (agricultura, por exemplo), evitando o descarte na natureza e sem comprometer a qualidade da água do rio paraíba do sul, que abastece a população da região.

Com a divulgação crescente de uma crise ambiental e as alternativas de desenvolvimento sustentável tornando-se cada vez mais populares, este acabou por se tornar um tema polêmico, principalmente do ponto de vista econômico, quando colocamos em ótica a apropriação de discursos e a criação de simbologias que, por si só agregam valor a produtos e agentes. Destacase ainda discussões sobre a garantia do direito de propriedade dos recursos naturais desde a apropriação efetiva até o direito de degradação dos mesmos, seja esta provocada pela falta de infraestrutura básica da comunidade presente no entorno, ou pelas externalidades negativas que derivam do processo produtivo industrial.

A localização da indústria analisada para embasar as discussões está consolidada e compreendese que a dinâmica de funcionamento já está estabelecida, entretanto, sugere-se a aplicação de novas metodologias e projetos para a melhoria das condições ambientais e da qualidade da água no rio Paraíba do Sul, com investimento em pesquisa e monitoramentos no sentido de melhorar a gestão dos recursos hídricos e geração de resíduos, indo além da legislação ambiental vigente, por meio de boas práticas ambientais com mais iniciativas próprias. Além disso, a prefeitura deve se fazer mais presente nas comunidades, principalmente no âmbito do saneamento básico e na execução de projetos em parceria com a iniciativa privada, o que diminuiria a pressão ambiental na área estudada e melhoraria a qualidade de vida dessas pessoas.

A análise realizada, serviu como forma de ilustrar e demonstrar a dificuldade de aplicação dos conceitos e de políticas públicas no que se refere às diretrizes do Plano Diretor Municipal nas questões ambientais e do poder público em geral, nas diferentes esferas (municipal, estadual e federal). Limitações também são encontradas por parte da indústria e do município neste processo, o que corrobora para necessidade de ampliação deste debate devido ao caráter multifacetado da questão ambiental em seus conceitos e agentes.

\section{AGRADECIMENTOS}

Os autores agradecem o apoio do Comitê de Bacia Hidrográfica do Baixo Paraíba do Sul e Itapaboana (CBH BPSI-RJ) por meio do diretor presidente João Gomes de Siqueira.

\section{REFERÊNCIAS}

AGÊNCIA DE BACIAS - AGEVAP. Estudos para Identificação, Localização e Quantificação das Causas da Proliferação de Plantas Aquáticas, Principalmente Macrófitas, ao Longo da Calha do Rio Paraíba do Sul, Inclusive Braços Mortos, Reservatórios e Afluentes. Relatório de Situação - Diagnóstico, Tecnogeo, Resende, 2012.

AGÊNCIA NACIONAL DE ÁGUAS - ANA. Outorgas emitidas pela ANA. Disponível em: http://www2.ana.gov.br/Paginas/institucional/SobreaAna/uorgs/sof/geout.aspx Acesso em: 22 maio 2015.

BONI, N.R.; ESPÍNDOLA, R.; GUIMARÃES, E.C. Uso de leguminosas na recuperação de um solo decapitado. In: SIMPÓSIO SUL-AMERICANO, 1.; SIMPÓSIO NACIONAL DE RECUPERAÇÃO DE ÁREAS DEGRADADAS, 2., Foz do Iguaçu, 1994. Anais [...]. Curitiba, FUPEF, 1994. p.563-568.

BOOTZ, M. PURAC - Líder Mundial na Preservação Natural de Alimentos. Revista Food Ingredients Brasil. FIB - Food Ingredients Brasil, São Paulo, SP, v. 15, p. 19 - 20, setembro, 2010. 
LAMMLE, L.; SANTOS, C. J.; AYER, J. E. B.; BARBOSA, A. I . G.
INTERAÇÕES SOCIOAMBIENTAIS NAS MARGENS DO RIO PARAÍBA DO SUL EM CAMPOS DOS GOYTACAZES/RJ: CONSIDERAÇÕES SOBRE O CASO DA INDÚSTRIA CORBION

BORKERT, C.M.; PAVAN, M. A.; LANTMANN, A. F. Considerações sobre o uso de gesso na agricultura. Piracicaba, Associação Brasileira para a Pesquisa da Potassa e do Fosfato - POTAFÓS, 1987.

BRAGA, F.A.; VALE, F.R. \& MUNIZ, J.A. Movimentação de nutrientes no solo, crescimento e nutrição mineral do eucalipto, em função de doses de gesso e níveis de irrigação. Revista. Brasileira de Ciência do Solo, v. 19, p. 69-78, 1995.

BRASIL, Ministério do Meio Ambiente. Manual de Impactos Ambientais: orientações básicas sobre aspectos ambientais de atividades produtivas. 2012.

CAMPOS DOS GOYTACAZES, Prefeitura Municipal de. Plano Diretor. 2008. Disponível em: http://www.campos.rj.gov.br/plano-diretor.php. Acesso em: 22 ago. 2019.

CORBION, Purac. Síntese: Sustainability. Disponível em: http://www.corbion.com/aboutcorbion/sustainability. Acesso em: 20 maio 2018.

DESIMONE, L. D., POPOFF, F. Eco-efficiency: the Business Link to Sustainable Development. MIT Press: Cambridge, MA, 2000.

DIAS, R. Gestão Ambiental: responsabilidade social e sustentabilidade. São Paulo: Atlas. 2006.

FARIA, T. P. Configuração do Espaço Urbano da Cidade de Campos dos Goytacazes, após 1950: novas centralidades, velhas estruturas. Anais do Encontro de Geógrafos da América Latina, v. 10, p. 4778-4799, 2005.

FOLADORI, G. Limites do desenvolvimento sustentável. In: Limites do desenvolvimento sustentável. Unicamp, 2001.

GIL, A. C. Métodos e técnicas de pesquisa social. 5. ed. São Paulo: Atlas, 2007.

INSTITUTO BRASILEIRO DE GEOGRAFIA E ESTATÍSTICA - IBGE (Brasil). Divisão regional do Brasil em mesorregiões e microrregiões geográficas. IBGE (1990). Disponível em: < https://biblioteca.ibge.gov.br/index.php/biblioteca-catalogo?view=detalhes\&id=22269>. Acesso em: 24/07/2020

LOPES, A. C. Evolução urbanística de Campos: aspectos de legislação. Campos dos Goytacazes: s. n, jul. 1988.

PRALON, A. Z.; MARTINS, M. A. Utilização do resíduo industrial Ferkal na produção de mudas de Mimosa caesalpiniaefolia, em Estéril de Extração de Argila, inoculadas com Fungos Micorrízicos Arbusculares e Rizóbio. Revista Brasileira de Ciência do Solo, v.25, p.55-63, 2001.

REED, D. Structural adjustment, the Environment, and Sustainable Development. London: Earthscan Publication, 1996.

SACHS, W. Anatomia Política do Desenvolvimento Sustentável. Revista Democracia Viva, ano I, n. 1. Rio de Janeiro: Moderna/Ibase, p. 11-23, 1997.

SANTOS, M. A Natureza do Espaço: Técnica e Tempo. Razão e Emoção. São Paulo: EDUSP, 2010.

SANTOS, R. F. Planejamento Ambiental: teoria e práticas. São Paulo: Oficina de Textos, 2004.

SCOTTO, G.; CARVALHO, I. C. de M.; GUIMARÃES, L. B. Desenvolvimento Sustentável. Petrópolis (RJ): Vozes, 2007.

SILVA, F. M.; BERGO, P. S.; JUNIOR, J. J. Desenvolvimento Sustentável e Química Verde. Quim. Nova, v. 28, n. 1, p. 103-110, 2005.

VIOLA, E. Reflexões sobre os dilemas do Brasil na segunda metade da década de 1990 e sobre uma Agenda de políticas públicas baseada na democracia, na equidade, na eficiência e na sustentabilidade. Trabalho para o workshop "Meio Ambiente, Desenvolvimento e Política de Governo: Bases para a Construção de uma Sociedade Sustentável no Brasil (Levando em Conta a Natureza). Olinda: Fundação Joaquim Nabuco, 1996.

YOUNG, C. E.; MOTTA, R. S. Measuring Sustainable Income from Mineral Extractions in Brazil. Resources Policy. v. 21, n. 2, p. 113-125, 1995.

\footnotetext{
${ }^{1}$ https://www.bndes.gov.br/wps/portal/site/home/imprensa/noticias/conteudo/20050927_not248_05
} 